\title{
Long-term trends in inventory investment in traditional market and post-socialist economies
}

\author{
Attila Chikán ${ }^{\mathrm{a}}$, Erzsébet Kovács ${ }^{\mathrm{b}}$, Zsolt Matyusz ${ }^{\mathrm{a}, *}$, Magdolna Sass $^{\mathrm{c}}$, Péter Vakhal ${ }^{\mathrm{b}}$ \\ ${ }^{a}$ Corvinus University of Budapest, Department of Logistics and Supply Chain Management, Fóvám tér 8, Budapest H-1093, Hungary \\ ${ }^{\mathrm{b}}$ Corvinus University of Budapest, Department of Operational Research and Actuarial Sciences, Fövám tér 8, Budapest H-1093, Hungary \\ ${ }^{\mathrm{c}}$ Centre for Economic and Regional Studies, Institute of Economics, Hungarian Academy of Sciences, Budaörsi út 45, Budapest H-1112, Hungary
}

\section{A R T I C L E I N F O}

\section{Article history:}

Received 31 October 2014

Received in revised form

30 April 2016

Accepted 14 June 2016

Available online 21 June 2016

Keywords:

National inventories

Global economy

OECD countries

Traditional market economies

Post-socialist economies

Macroeconomic indicators

\begin{abstract}
A B S T R A C T
Inventories form a small but important part of national wealth and constitute the most volatile component of GDP. Their moves are important indicators of the dynamics of the economy, both at the micro and macro level. In this paper, the authors venture to explain long-term macroeconomic inventory investment trends from new perspectives.

We compiled a data set of 24 OECD countries for the 1970-2011 time period and addressed three sets of questions:

- How can inventory investment be characterised in the sample countries, and what are the general tendencies? Does the analysis on the substantially larger data set (compared to those in our previous studies) verify earlier results regarding the declining global trend in inventory investment and the convergence of inventory features in different countries?

- A quarter of a century ago, a substantial change in the economic systems of certain OECD countries took place: the transition of Central-Eastern European countries from planned to market economies. The difference in inventory behaviour in the two sets of countries was obtrusive before the transition the changes following the transition reveal very important consequences of systemic changes.

- Are there substantial connections between fundamental country characteristics and inventory behaviour? Can regression and correlation analysis reveal some decisive relationship between certain macroeconomic indicators and inventories?

Our analysis resulted in mostly positive or at least meaningful answers to the above questions and opened up a broad field for further research.
\end{abstract}

(C) 2016 Elsevier B.V. All rights reserved

\section{Introduction}

As a result of globalisation, the comparison of performance and characteristics of various countries or groups of countries is now an integral part of economic analysis, both to evaluate the current situation (and the processes leading to it) and to formulate strategies and future steps. There are a number of different ways to compare economies. In addition to the many academic papers, international institutions (The World Bank, UNIDO, OECD, etc.), think tanks (such as the World Economic Forum and the Brookings Institution), and major economic media (The Economist or the

\footnotetext{
* Corresponding author.

E-mail addresses: chikan@uni-corvinus.hu (A. Chikán), erzsebet.kovacs@uni-corvinus.hu (E. Kovács),

zsolt.matyusz@uni-corvinus.hu (Z. Matyusz), sass.magdolna@chello.hu (M. Sass), peter.vakhal@uni-corvinus.hu (P. Vakhal).
}

Economics Blog), many consulting groups and even national governments publish regular or occasional analyses and forecasts.

Inventories are an important component of economic activity, and cross-country analysis of inventories has drawn considerable interest. Focusing on the business management of inventories, the largest stream of cross-country inventory research compares the principles and practices of companies, most recently supply chains. Economics-based comparisons address mainly national or sectorial inventories and are less comprehensive than the business literature. Until recently, the relative lack of reliable and well organised data was a significant barrier to the economic analysis of inventories in many countries, with the notable exception of the United States, where relevant and detailed data have been available for a long period of time. Despite the difficulties involved in international comparison in general and in national inventory behaviour in particular, we decided to study and compare inventory investment in various countries. Our interest was 
originally piqued many years ago by the strange differences between inventories in market and planned economies, and we would later extend this interest to more general areas.

This paper addresses the inventory behaviour of OECD economies, which are relatively similar in terms of their economic systems. The objective of the paper is twofold: (1) We attempt to identify and explain the main tendencies of inventory behaviour in the most developed economies and (2) highlight the effect of the transition from socialist (planned) to market economies.

The structure of the paper is the following. Section 2 gives an overview of the relevant literature. Section 3 briefly describes the database and the methodology. In Section 4, we characterize 18 OECD economies between 1970 and 2011 and provide an explanation for their inventory behaviour. In Section 5, we compare inventory investments in these economies (we refer to them as 'traditional market economies' or TMEs) and six Central and Eastern European former socialist economies, demonstrating the consequences of the transition process. We examine the fit of the data of these countries (we refer to them as 'post-socialist economies' or PSEs) to the general trends in inventory data. Section 6 summarizes the results of correlation and regression analysis, calling attention to differences in the inventory behaviour of individual countries. We close with a conclusion and suggestions for further research.

\section{Literature review}

The inventory literature is rich - we highlight only those contributions that are the most important to the research background of our paper. We do not address the vast literature on business management of inventories, focusing only on some of the economics aspects. Economics approaches can be classified as microeconomic or macroeconomic. Blinder and Maccini (1991) established the link between them. Their line of research was followed among others by Lovell (1994, 1996), Hay and Louri (1996) and McCarthy and Zakrajsek (1999).

Our research is based primarily on macroeconomic considerations. Inventories are rarely included as separate variables in dynamic general equilibrium models, presumably due to their smallness. Macroeconomists rely more often on the inclusion of fixed investment and consumption variables in their models; attempts to include inventories in theoretical macro models may have posed various problems for the models in question. At the same time, this inclusion may improve the models or may alter their predicted outcomes (see, among others, Forrester, 1976; Blinder, 1980; Fiorito, 2003). Furthermore, there is mixed evidence concerning the improvement of growth forecasts when inventory data are added (see, e.g., Clausen and Hoffmaister, 2010; Ghebrihiwet, 2011). We considered simultaneous and structural models as well for our research (see, for example, Khan and Thomas, 2004; Wen, 2007) but found that because our research is based on panel data and not purely on time series, we cannot apply this methodology.

The most advanced inventory research is based on theories of economic cycles. This approach is explained and justified by the fact that while inventory investments constitute only a relatively small proportion of the use of GDP, they are responsible for a large proportion of fluctuation in GDP in most countries and cases. In a seminal paper, Ramey and West (1997) convincingly stated that inventories are a useful source of information in business cycle research. They presented a linear quadratic model and showed the pro-cyclical movement of inventories as well as the persistence of the inventory-to-sales ratio. Thus, it is no wonder that while there is well-founded and extensive research on inventory fluctuations (see, for example, Bils and Kahn, 2000; Maccini and Pagan, 2013), there is much less research addressing the level of inventory investments, in particular with regard to international comparisons and analysis of long-term trends in inventory behaviour in a group of countries, which is the focus of our study. Amongst the important papers on the level of inventories, see, e.g., Bouthevillain and Eyssartier (1997) for developed countries; Kaneko (2005) for Japan; Guasch and Kogan (2001) for developing countries; and Bergson (1989) for comparison of certain market economies and socialist countries. Our particular approach is concentrating on the analysis of connections between inventories and other macroeconomic indicators and it has its predecessors in Chikán and Kovács (2009) and Chikán et al. (2011). In this paper, we use longer time series for more countries than previously.

Earlier analysis at the macro level examined the relationship between the sectorial structure of the economy and inventory behaviour. Chikán et al. (2011) analysed 15 OECD countries from this point of view and found a positive correlation between the share of agriculture and manufacturing in GDP and inventory intensity and a negative correlation between the share of services and inventory intensity.

The study of macroeconomic inventory investments began several years ago. Our research was triggered by the new features of post-transition inventory behaviour of the so-called former socialist economies. The striking difference between the characteristics of inventory investment of these countries and those of market economies had already been recognised and explained earlier (see, e.g., Kornai, 1971; Chikán, 1981). However, the rapid adjustment in inventory behaviour after the transition process raised new questions and widened the scope of research. More details regarding this area of research can be found in Section 5 .

\section{Methodology and database}

Inventory investment is measured as the ratio of annual change in inventories (dI) and GDP (henceforth dI/GDP) - both of which can be found in the national accounts statistics. Based on the logic of Markowitz's (1959) portfolio analysis, we rely to a large extent on the combination of the mean and standard deviation as a measure of volatility.

After having reviewed the available databases (UN National Accounts, UNCTAD, Eurostat, OECD), we decided on the OECD database (OECD, 2013) for several reasons, the first being its relative reliability. The OECD database contains information on all of the major countries and variables listed in the Eurostat database while also including important non-European economies. The data in these two databases are synchronized, but the OECD database is preferable because of the broader country coverage. The OECD database is also homogenous and relies on quality data. The UNCTAD database displays longer time series but only by compiling different databases together in the case of each country, which reduces data reliability. The UN National Accounts database uses OECD, Eurostat and/or national statistics data for these countries. Although these data in theory should be the same, in practice, there may be some inconsistencies because of asynchronous data updates and not perfect harmonisation across the different sources. For many PSEs, data are missing before the transition era (1990-1993), or an estimation procedure was used that produced inconsistent and thus unreliable time series compared to other research focusing on this time frame. Thus, we found the OECD database to be the longest homogeneous and most reliable data source available.

We use aggregate national and international statistics over time as time series data and take samples from the OECD member countries at different time periods. We analyse panel data as a type of longitudinal data, as we are interested in describing 
inventory changes over time and for the same countries. Given the inventory behaviour of countries in relation to other macroeconomic variables observed across time, our input data for multivariate statistical analysis has three dimensions (variable, country, and year). This type of analysis is well known and widely used in econometrics and the social sciences, as shown in Maddala (2001) and Wooldridge (2002).

Our initial list of OECD countries consisted of 28 traditional market economies (TMEs) and six post-socialist economies (PSEs). The time horizon that was chosen was the period between 1970 and 2011. The starting year, 1970, marks the availability of yearly inventory investment data for many OECD countries, while 2011 was the last available year when our research was started. For different reasons, we excluded ten traditional market economies from the analysis:

1) Certain countries have only a partial dI/GDP dataset: Austria (1976-2011), Chile (1996-2011), Ireland (1995-2011), Korea (1975-2011), Portugal (1988-2011) and Switzerland (19802011).

2) The data for Greece, Mexico and Turkey was too volatile data, which prompted concerns about reliability - descriptive statistics and exploratory examination of the time series indicated that although the data for these countries are available for 1970-2011, they do not seem to be robust enough for the full time horizon.

3) Luxembourg's economic structure is strongly skewed towards services, and therefore, its total inventory level is a definite outlier given the much lower inventory intensity of services compared to manufacturing.

The final set of countries was the following:

(1) Traditional market economies (TME): Australia, Belgium, Canada, Denmark, Finland, France, Germany, Iceland, Israel, Italy, Japan, Netherlands, New Zealand, Norway, Spain, Sweden, United Kingdom, USA.

(2) Post-socialist economies (PSE): Czech Republic, Estonia, Hungary, Poland, Slovakia, Slovenia.

In some parts of the analysis, we omitted one or two other countries for special reasons explained at the relevant places.

We have found it useful to establish two subperiods within the full time horizon considered. An approximate analysis of the data (observing the means and standard deviations) shows that the first and second part of the full period may have different characteristics. Indeed, we have identified both economic and business reasons (see Section 4) to set the breakpoint at the beginning of the 90s. 1994 was chosen because this is the year that dI/GDP data began being reported in the post-socialist countries, which made it possible to perform a joint analysis of the two groups of countries.

Three topics of interest were identified at the beginning of our work:

1. In earlier papers (see references in the previous section), we found that both the means, and the standard deviations of inventory investments show a decreasing tendency over time in the majority of developed economies. We wanted to verify this observation using a longer and more consistent database than previous databases.

2. We wanted to determine why PSEs exhibited a change in their inventory investment behaviour that began to resemble that of TMEs immediately after the beginning of the transition process and why, at the end of the analysed period, they showed a similar pattern but at a lower level of development.

3. Despite the very important global explanatory factors behind these trends, there are observable and persistent differences among the various countries regarding the level and fluctuation in their inventory investment. (Various studies called attention to the country-level differences in changes in inventories and their large volatility; see e.g., Ramey and West, 1997). We wanted to observe the nature of these differences and the reasons for them and determine the extent to which the individual countries depend on global trends, i.e., the ability of a unified explanatory model to explain their behaviour.

\section{Analysis: characteristics of traditional market economies over time and countries}

In earlier research, we found that both the means and standard deviations of annual inventory investment (dI/GDP) have a decreasing tendency over time. Fig. 1 shows the range of dI/GDP values of the 17 TMEs between 1970 and 2011. As we focus on the trend of dI/GDP, we did not label individual countries but highlighted the range of these separate trendlines. The annual mean $\mathrm{dI} /$ GDP values of the 17 TMEs are also displayed by the solid black

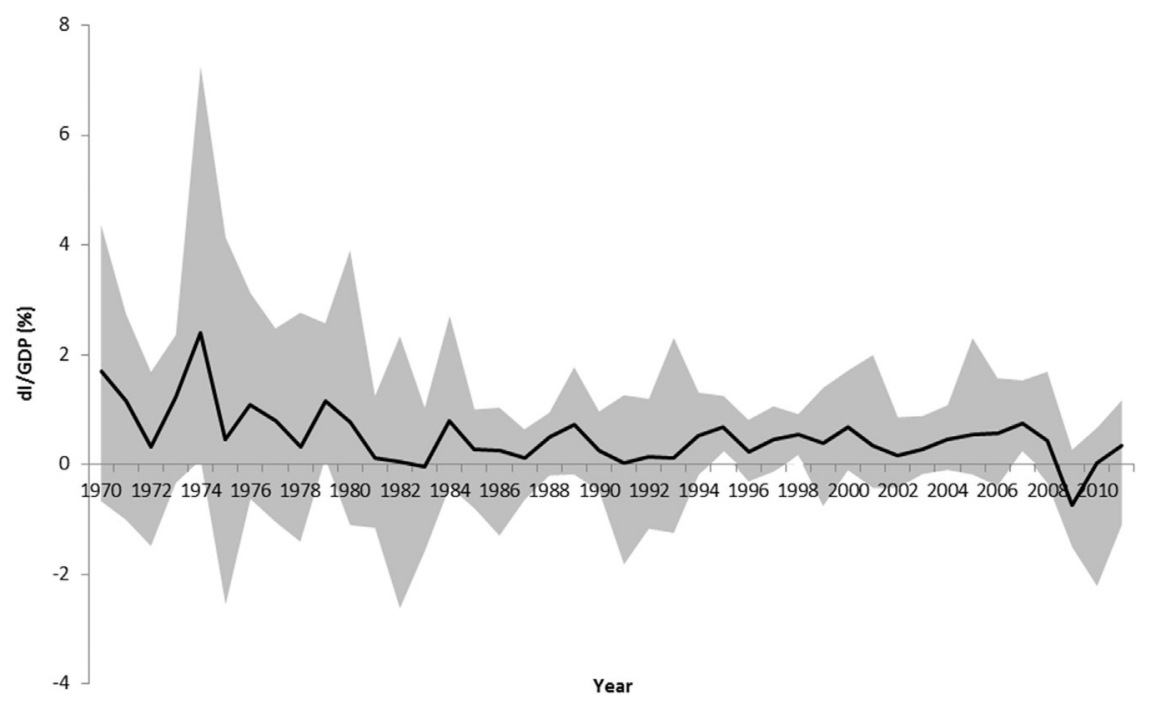

Fig. 1. dI/GDP values of 17 TMEs (1970-2011) (Norway omitted). 


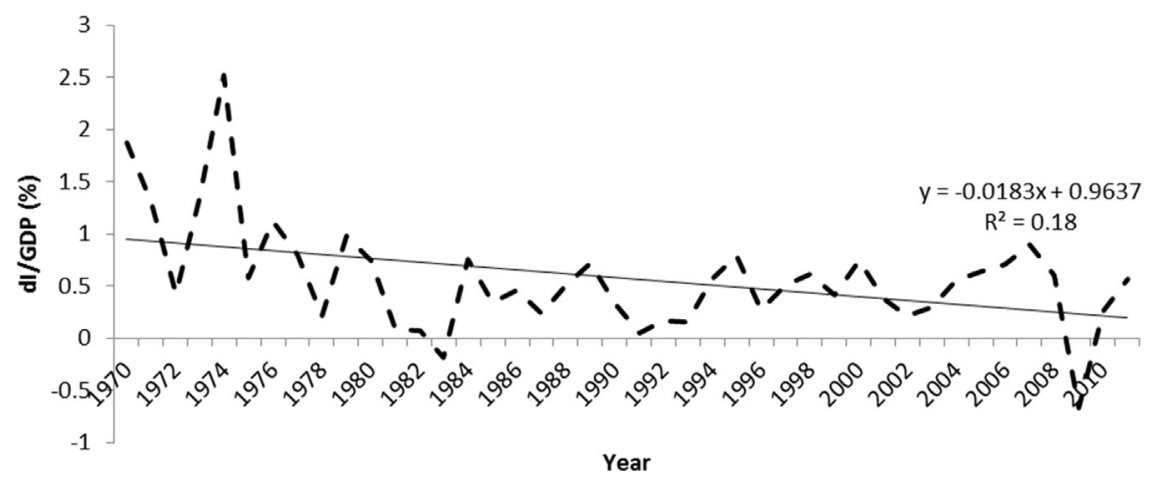

Fig. 2. Mean dI/GDP values (18 TMEs, 1970-2011).

line. It can be seen that dI/GDP data are much more volatile in the first part of the time horizon than in the second part, as if the countries eventually converged in terms of inventory investment behaviour towards a generally lower level. (Norway is omitted from this figure because of its extreme behaviour. Norway's inventory data are highly influenced by the substantial oil and gas reserves and their exploitation; see Ministry of Petroleum and Energy, 2013).

\section{1. $d I / G D P$ trends}

Figs. 2 and 3 show the yearly means and standard deviations of dI/GDP. The linear trends displayed in Figs. 2 and 3 show that although the slope is not too steep, there is indeed a decreasing trend for both the means and standard deviations of dI/GDP. The financial crisis did not influence this phenomenon - these decreasing trends would have persisted if we examined the time horizon only up to 2008. Both trends are statistically significant. In the case of mean $\mathrm{dI} / \mathrm{GDP}$, the beta value is -0.018 with a standard error of 0.006 ( $p=0.005)$, while for standard deviation of dI/GDP, the beta value is -0.016 with a standard error of 0.004 ( $p=$ $0.000)$.

\subsection{Connection between the means and standard deviations}

To check the stability of the trends described in the previous section, we analysed the means and the standard deviations together. Fig. 4 shows the scatterplots of 17 TMEs (Norway omitted) for the total period analysed, 1970-2011, and for two subperiods, 1970-1993 and 1994-2011. Each dot represents a country with its respective mean and standard deviation of dI/GDP.

If we observe the full time horizon (Fig. 4a), there is only a weak positive relationship between the mean and standard deviation of $\mathrm{dI} / \mathrm{GDP}$. We investigated whether this result masks some marked difference between the subperiods. In the first subperiod (Fig. 4b), we found no meaningful relationship between the mean and standard deviation of dI/GDP. The second subperiod, however, shows a definite relationship between the two with an R-squared value of 0.42 , implying that the inventory investment behaviour of the countries has changed and the inventory investment of countries with a higher mean for dI/GDP became more volatile. We will further investigate this finding in Section 5 for the TMEs and for the larger country group including the PSEs as well.

\subsection{Explanation of the declining trends and their volatility}

There is a common understanding among most economists that it is possible to meaningfully explain macroeconomic inventory trends if we take into account firm behaviour and its influence on aggregate processes (see Blinder and Maccini, 1991; Lovell, 1994; Siems, 2005). The declining trend in inventory investment was already discovered in the 1980s, and many authors referred to the widespread use of "Japanese" management technologies, commonly (but not precisely) referred to as "JIT" (just-intime) technology, on the basis of which many authors advocated the emergence of "stockless production" (first defined by Hall, 1983). Inventories were identified as wasteful and were condemned as a source of company-level inefficiency.

No question, management technologies developed at a revolutionary speed in the late 1970s and in the 1980s, which certainly contributed more than anything else to the general decline in inventory investment. Undoubtedly, the use of advanced inventory management methods (eventually considered a component of "lean management") has spread world-wide, mainly due to the parallel acceleration of globalization. However, in the 1980 s several other global processes developed, stemming in large part from business-level efficiency seeking. The growth and sophistication of customer demand as well as the increasing complexity of

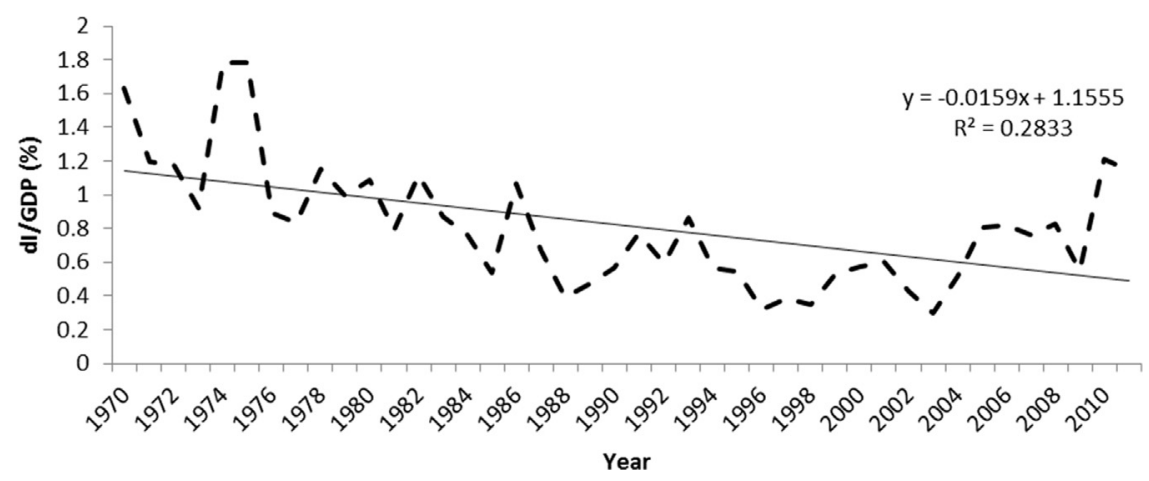

Fig. 3. Standard deviation of dI/GDP values (18 TMEs, 1970-2011). 

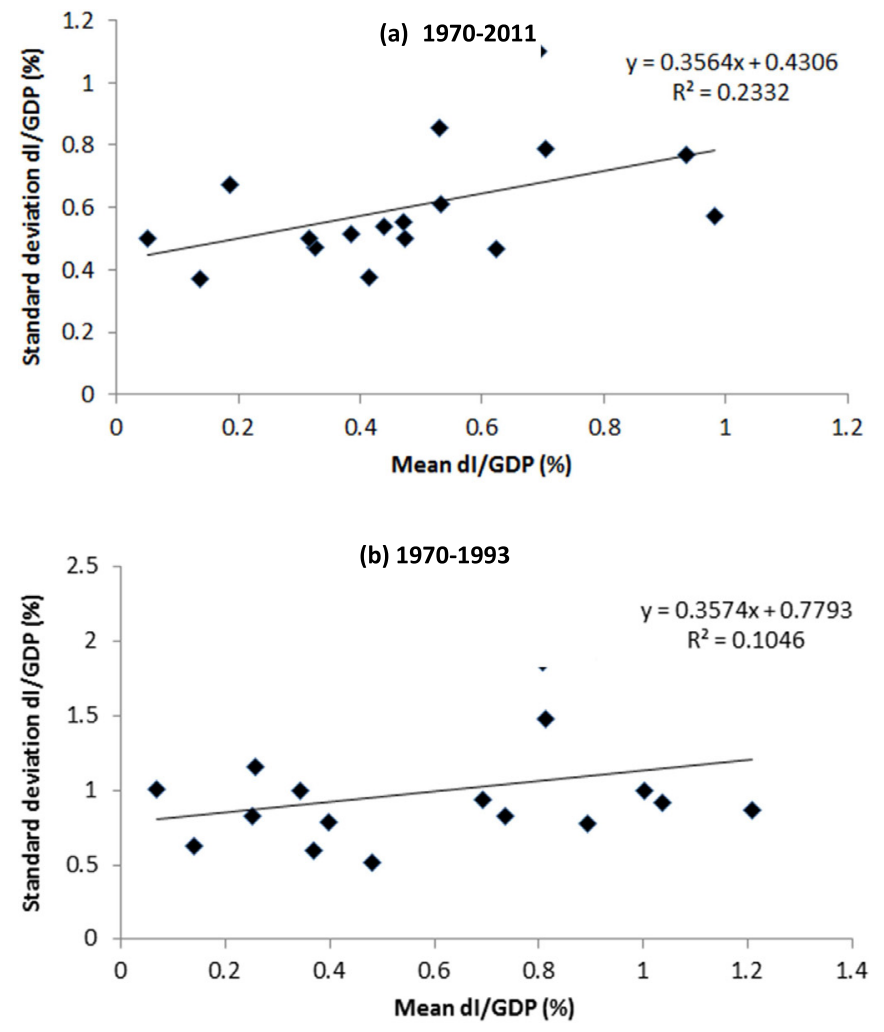

(c) 1994-2011

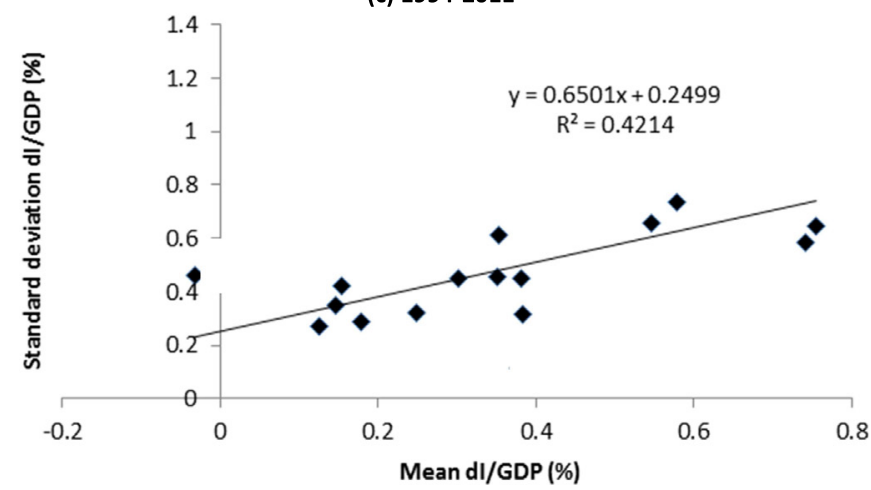

Fig. 4. Mean and standard deviation dI/GDP values of 17 traditional market economies (Norway omitted).

global production and distribution processes led to a situation where even if nearly all business units managed inventories more effectively than previously, there would be little gains from these individual efforts at the macro level (Prahalad and Hamel, 1990; Lee and Billington, 1992; Chikán, 1996). This led to varying patterns of inventory investment after the mid-1990s, which, however, still exhibited the tendency of slow decline. Recent studies claim that the role of inventories in today's management processes is changing (to be more active), which may eventually lead to at least partial counterbalancing of the consequences of more effective inventory management techniques (Chikán, 2007; Hofer et al., 2012). The nearly universal drop in inventories during and after the global crisis of 2008 can be attributed to the sharp fall in the real economy right after the beginning of the financial crisis. This was a one-time effect, and inventories started to climb back to their usual levels soon afterwards.
Table 1

Inventory investment as a \% of national income in current prices. Source: Chikán, 1990.

\begin{tabular}{lll}
\hline Country & Time period & $\begin{array}{l}\text { Average inventory investment/national } \\
\text { income }\end{array}$ \\
\hline Bulgaria & $1970-1972$ & 10.9 \\
Czechoslovakia & $1970-1984$ & 7.3 \\
Yugoslavia & $1970-1983$ & 8.1 \\
Poland & $1970-1984$ & 5.8 \\
Hungary & $1970-1984$ & 7.6 \\
Soviet Union & $1970-1974$ & 10.5 \\
\hline
\end{tabular}

\section{Inventories in different economic systems - a joint analysis of traditional market and post-socialist economies}

In the middle of the 1970s, inventory accumulation became a hot topic in Central and Eastern European economies (from today's perspective, we refer to them as PSEs). By that time, most of these countries had been through varying degrees of economic reform, which definitely brought some increases in efficiency. However, despite governmental efforts in these countries, annual inventory investment remained at very high levels, more than three to four times higher than in developed market economies. Because of the sporadic availability and limited reliability of data from this period, it is only possible to provide an illustrative collection of data in Table 1.

It was not before the beginning of the 1980s (Kornai, 1980; Chikán, 1981) that the research determined the reasons for this stubborn feature, the most immediate being the "decentralised" allocation of inventories in the economy.

In shortage economies, unlike in market economies, it is easy to sell but hard to buy, consequently the majority of inventories are held not by suppliers (e.g., by manufacturers in the form of finished goods) but by potential users, whose objective is to protect themselves against frequent disturbances in supply. This phenomenon is the exact opposite of the situation in market economies, as described in Kahn (1992). This input-side uncertainty led to the inventory structure illustrated in the first rows of Table 2. It should be noted that the $\mathrm{I} / \mathrm{O}$ inventory ratio in the TMEs in the same period was usually approximately 1.0.

The general overdemand experienced in the markets of these economies reproduces shortages, which in turn lead to the described hoarding behaviour of firms. It is evident that at the same level of demand satisfaction, this decentralisation causes excess

Table 2

Inventory structure in the manufacturing industry by stage of fabrication Source: Chikán, 1994.

\begin{tabular}{llllll}
\hline & & Input & Work in process & Output & 1/O ratio \\
\hline Czechoslovakia & & & & & \\
Average & $1980-85$ & 56.7 & 24.7 & 18.6 & 3.07 \\
& 1988 & 54.9 & 22.5 & 22.6 & 2.43 \\
& 1989 & 53.6 & 22.1 & 24.3 & 2.21 \\
& 1990 & 50.0 & 27.1 & 22.9 & 2.18 \\
Hungary & & & & & \\
Average & $1980-85$ & 72.5 & 15.6 & 11.9 & 6.1 \\
& 1988 & 72.2 & 13.6 & 14.0 & 5.16 \\
& 1989 & 71.2 & 13.4 & 15.3 & 4.65 \\
& 1990 & 68.1 & 12.3 & 19.4 & 3.5 \\
Poland & 1991 & 63.0 & 13.4 & 23.6 & 2.67 \\
Average & & & & & \\
& $1980-85$ & 63.0 & 22.9 & 14.1 & 4.49 \\
& 1988 & 64.0 & 22.6 & 13.4 & 4.78 \\
& 1989 & 61.4 & 20.3 & 18.3 & 3.36 \\
& 1990 & 54.8 & 24.1 & 21.1 & 2.6 \\
\hline
\end{tabular}




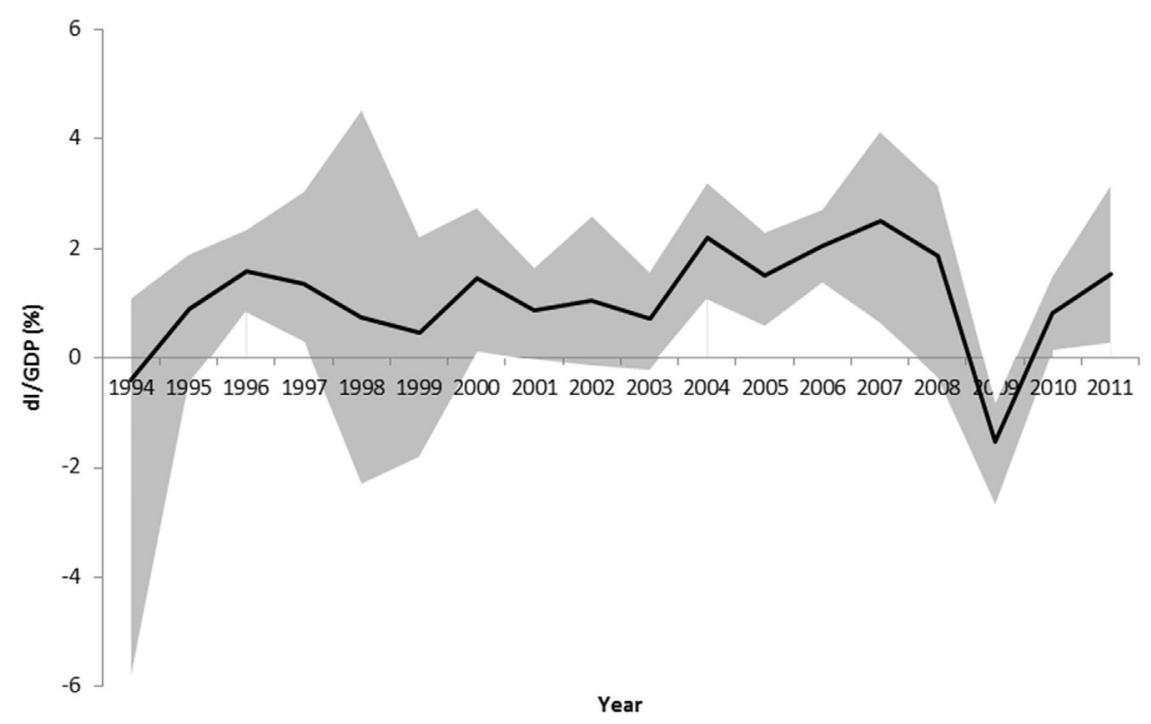

Fig. 5. dI/GDP values of six post-socialist countries (1994-2011).

inventory holding in the economy as a whole.

János Kornai gave a full explanation for the sequence of logic of these processes (Kornai, 1980), indicating that it stems from soft budget constraints, the most fundamental characteristic of firm operation in socialist economies. Thus, it was no surprise that after the transition process started at the turn of the 1990s, inventory investment behaviour together with the structure of inventories drastically changed: In a few years, hoarding inventories on the input side were replaced by increased output inventories waiting to be purchased. Chikán (1994) describes the process and data of the years of transition to illustrate the rapid change.

The purpose of our research is to reveal whether inventory development in the PSEs fits into the patterns we observed in TMEs.

The availability of data made it possible to examine the inventory behaviour of six PSE countries: the Czech Republic, Estonia, Hungary, Poland, Slovakia and Slovenia. Fig. 5 shows the range of dI/GDP values of the six PSEs between 1994 and 2011. Just as in the case of Fig. 1, we wanted to see how the individual country trends move together and thus highlighted the range and the annual mean of the dI/GDP values. It can be seen that as in the case of the TMEs, PSEs initially behaved in a more volatile fashion and then started to converge in terms of inventory investment behaviour.

Figs. 6 and 7 compare the means and standard deviations of $\mathrm{dI} /$ GDP of TMEs and PSEs. PSEs clearly show a higher mean and standard deviation well after their transition to capitalism was

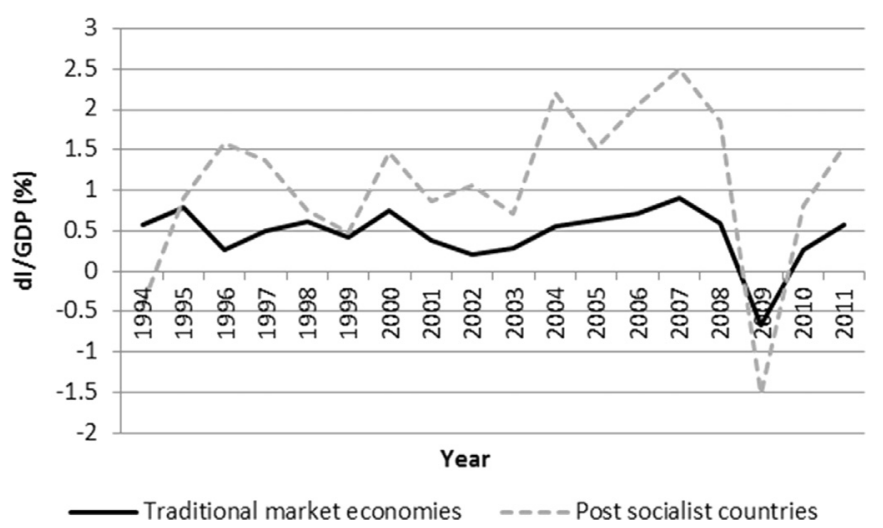

Fig. 6. Means of dI/GDP values (18 traditional market economies and 6 post-socialist countries, 1994-2011).

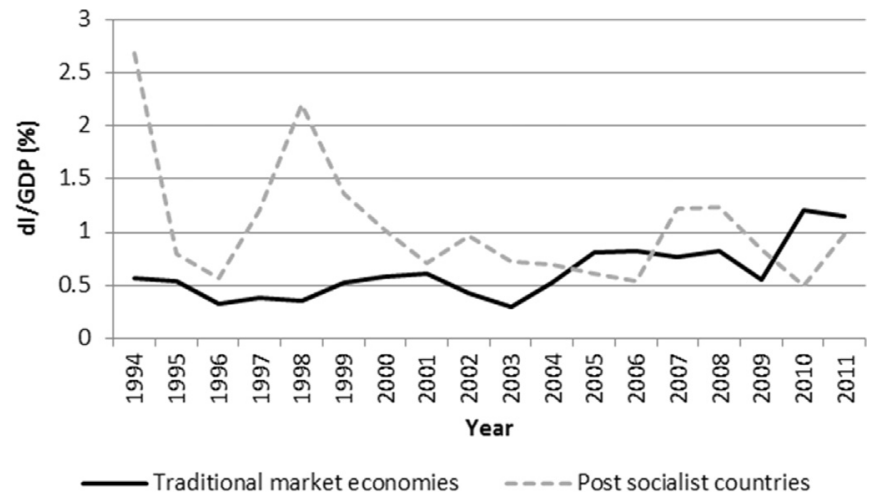

Fig. 7. Standard deviations of dI/GDP values ( 18 traditional market economies and 6 post-socialist countries, 1994-2011).

formally completed. Their inventory investment behaviour became more similar to that of TMEs, although not as much as many would have expected. This suggests existing persistent systematic difference between the two groups of countries.

Fig. 4 shows that there is a trend in TMEs between the mean and standard deviation of $\mathrm{dI} / \mathrm{GDP}$. We were interested in seeing how PSEs fit this trend. Fig. 8 shows the joint scatterplot of TMEs and PSEs for the subperiod of 1994-2011. Each dot represents a country with its respective mean and standard deviation of $\mathrm{dI} /$ GDP. TMEs are marked with squares, while PSEs are marked with triangles. We again omitted Norway and also Slovakia from the PSE group. Both countries behave in a special way: Norway's

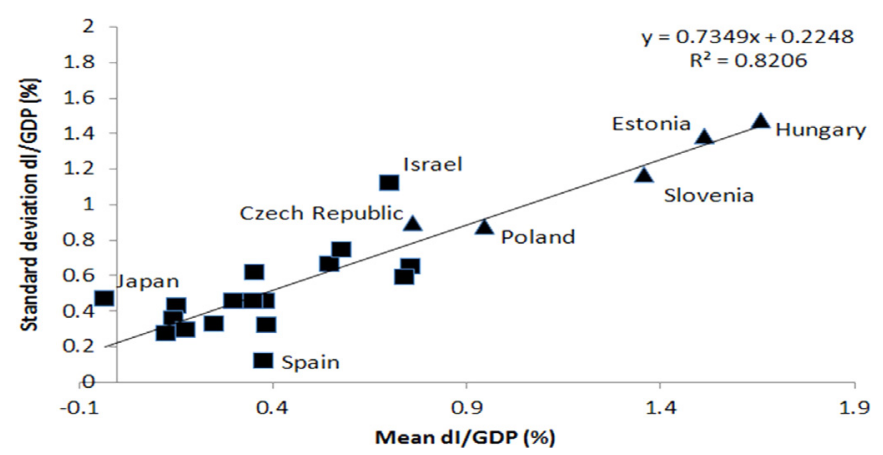

Fig. 8. Mean and standard deviation dI/GDP values of 17 TMEs and 5 PSEs (19942011). (Norway and Slovakia omitted). 
behaviour was explained in Section 4, while in the case of Slovakia (which has a very low mean and very high standard deviation), a possible explanation for the extreme behaviour may be the slow process of separation from the former Czechoslovakia. Although by 1993 the Czech Republic and Slovakia became separate entities, several issues were not resolved until 1999 and the two economies have continued to operate in close cooperation, which may be causing the distortion in the early Slovak statistics. The scatterplot shows a very strong relationship between the mean and standard deviation of $\mathrm{dI} / \mathrm{GDP}$ with an R-squared value of 0.82 , which supports our previous findings and implies that countries with a higher mean of dI/GDP tend to have a higher standard deviation of dI/GDP.

\section{Relationship between inventories and other macro- economic indicators}

As Section 4 shows, countries differ in their long-term inventory investment behaviour, and we wanted to determine whether some macroeconomic indicators could explain this tendency. There are several structural characteristics of an economy that can influence its inventory investment behaviour. We considered nine of them in our analysis.

- Three indicators characterize the internal use of GDP; i.e., they represent three types of GDP expenditure. they can be considered as alternatives to inventory investment, or rather inventory investment can be considered as a kind of residual after these alternatives of spending are used.

1. Private consumption (PC): measured in \% of GDP;

2. Government consumption (GC): measured in \% of GDP;

3. Gross fixed capital formation (GFCF): measured in \% of GDP;

- Openness shows the extent to which a country is embedded in international relationships, i.e., the extent to which it is integrated into the global economy.

4. Openness (OPEN): Calculated by the sum of import and export, measured in \% of GDP;

- The two most common indicators to characterize an economy are the level of development and the rate of growth, for which the following indicators are used:

5. GDP/capita (CAPITA): used as a proxy for economic development, measured in US\$;

6. GDP growth rate (GROW): annual, measured at constant prices in \%;

- The level of centralization of an economy indicates the extent to which the government intervenes in the economy and makes decisions regarding the use of GDP as opposed to the private sector (and households); this is measured by the following indicator:

7. Total tax revenue (TTR): used as a proxy for economic policy centralization, measured in \% of GDP;

- The industry and sector composition of an economy may be important as there are substantial differences in the inventory intensity of various sectors:

8. Share of manufacturing activities (MFG): used as a proxy for industrial structure, measured in \% of gross value added
Table 3

Summary of significant linear correlations of dI/GDP with the selected macroeconomic variables $(+$ : positive correlations; - : negative correlations; 0 : mixed correlations).

\begin{tabular}{llll}
\hline $\begin{array}{l}\text { Correlation of dI/GDP } \\
\text { and... }\end{array}$ & $\begin{array}{l}\text { Number of significant correlations in the given period } \\
\text { (out of 18 TMEs) }\end{array}$ \\
\cline { 2 - 4 } & $1970-2011$ & $1970-1993$ & $1994-2011$ \\
\hline PC & $6(-)$ & $7(-)$ & $6(-)$ \\
GC & $12(-)$ & $12(-)$ & $7(-)$ \\
GFCF & $9(+)$ & $9(+)$ & $1(+)$ \\
OPEN & $5(-)$ & $4(-)$ & $2(0)$ \\
CAPITA & $8(-)$ & $9(-)$ & $4(0)$ \\
GROW & $14(+)$ & $12(+)$ & $14(+)$ \\
TTR & $8(-)$ & $10(-)$ & $3(+)$ \\
MFG & $8(+)$ & $9(+)$ & $4(+)$ \\
TRADE & $3(+)$ & $4(+)$ & $2(0)$ \\
\hline
\end{tabular}

(GVA);

9. Share of domestic trade activities, wholesale and retail (TRADE): used as a proxy for industrial structure, measured in $\%$ of gross value added (GVA).

As we would like to investigate the relationship between $\mathrm{dI} /$ GDP and these macroeconomic variables in TMEs and only a total of 42 observations are available for each country, regression analysis cannot be used because of overfit and severe multicollinearity. Nonetheless, we could examine the correlations of $\mathrm{dI} /$ GDP and the selected macroeconomic variables.

Linear correlations of dI/GDP with the selected macroeconomic indicators show certain regularities. For most indicators, there is a clear relationship pattern with dI/GDP: Where correlations are significant, they have the same sign in - practically - all countries. The results indicate that PC, GC, OPEN and CAPITA tend to have a negative relationship with $\mathrm{dI} / \mathrm{GDP}$, while in the case of GFCF, GROW, MFG and TRADE, the relationship tends to be positive. TTR shows mixed behaviour: In the first subperiod, the relationship with $\mathrm{dI} / \mathrm{GDP}$ was negative, while in the second subperiod, it became positive, but the number of significant correlations was very low. Table 3 summarizes the findings, while Tables A1-A3 in Appendix A present the correlations in detail by country and variable to give a more complete picture. The countries with the most significant correlations are Belgium, France, Germany, Japan, Sweden and the USA. The number of significant correlations usually drops in the second subperiod.

If we compare the linear correlations of dI/GDP with the selected macroeconomic indicators in the case of TMEs and PSEs in the second subperiod, we find similar patterns, although the number of countries (and hence the possible number of significant correlations) is much less in the case of the PSEs. Nonetheless, these correlations display a clear trend with dI/GDP: Where correlations are significant, they have the same sign in all countries. The results indicate that PC, GC and TRADE tend to have a negative relationship with dI/GDP, while in the case of OPEN, GROW and MFG, the relationship tends to be positive. Table 4 summarizes the findings, while Table A4 in Appendix A displays the detailed indicators of correlations by country and variable. GROW and OPEN are the two indicators that have a significant correlation in at least half of the PSEs. In the remaining cases, one or two PSEs show significant correlations between the indicator and dI/GDP, while no significant correlation can be found in the other PSEs. Slovenia has the highest number of significant correlations, while Slovakia has only one. If we compare the PSE correlations with the TME correlations of the same time period, we can see that PC, GC, GROW and MFG show the same relationship pattern in both 
Table 4

Summary of significant linear correlations of dI/GDP with the selected macroeconomic variables ( + : positive correlations; - : negative correlations; 0 : mixed correlations).

\begin{tabular}{lll}
\hline $\begin{array}{l}\text { Correlation of dI/ } \\
\text { GDP and... }\end{array}$ & $\begin{array}{l}\text { Number of significant cor- } \\
\text { relations in the given peri- } \\
\text { od (out of 6 PSEs) } \\
1994-2011\end{array}$ & $\begin{array}{l}\text { Number of significant corre- } \\
\text { lations in the given period } \\
\text { (out of 18 TMEs) } \\
1994-2011\end{array}$ \\
\hline PC & $2(-)$ & $6(-)$ \\
GC & $1(-)$ & $7(-)$ \\
GFCF & - & $1(+)$ \\
OPEN & $3(+)$ & $2(0)$ \\
CAPITA & - & $4(0)$ \\
GROW & $5(+)$ & $14(+)$ \\
TTR & - & $3(+)$ \\
MFG & $1(+)$ & $4(+)$ \\
TRADE & $1(-)$ & $2(0)$ \\
\hline
\end{tabular}

groups.

Due to the limited number of PSEs in our analysis, we were able to identify fewer correlations between dI/GDP and macroeconomic variables, but it seems that $\mathrm{dI} / \mathrm{GDP}$ shows a positive relationship with GROW and MFG and a negative relationship with PC and GC regardless of the type of countries investigated.

\section{Conclusions}

We analysed three research questions in this paper. We wanted to see

1. whether we can draw meaningful conclusions regarding the long-term trends of national inventory investment;

2. the impact of the transition process on inventories in the postsocialist economies;

3. whether we can reveal important connections between inventory investment and macroeconomic characteristics of various countries.

Our work regarding the first question was supported by a series of earlier publications by some of the authors of this paper. The current research is novel in that we had a more reliable and considerably longer time series for a wider set of countries, which made more comprehensive analysis possible. We found that in accordance with previous results, inventory investment declined in the first part of the time horizon, mainly due to the spread of advanced business management of inventories. However, since the middle of the nineties, this trend has ended, and inventory investment is more or less stagnating, mainly due to the increased requirements of supplying customers and the increased complexity of the economy. The stability of the above trend is supported by the relatively low standard deviations, which are rather closely connected to the means.

The transition process from planned to market economy served as a kind of laboratory to compare the effects of the changing behavioural rules of companies with the systemic changes - one of the most important indicators of which was the changing inventory structure of the economy. Our research has verified this change, showing that the increased importance of the market and customer satisfaction leads to more rational inventory allocation and, as a consequence, a lower national inventory investment ratio.

The many trials based on regression and correlation analysis of inventory investment and the macro-level indicators of the characteristics of 18 traditional market economies (post-socialist economies were not considered in this analysis due to their short time series) have led to modest but interesting results. There is a rather strong positive correlation between inventory investment and GDP growth, and the relationships with other indicators are typically weak but steady. There seems to be no way of constructing a general and statistically significant regression model fitting the connections between inventory investment and components of GDP expenditure.

Further investigations are necessary regarding many aspects of the paper. Trends may be analysed further by incorporating new variables. Factor and cluster analysis may be used to classify the countries in the sample and discover further essential explanations for changes in countries and time. Further economic policy analysis may shed light on some of the reasons for differences in time and space.

\section{Appendix A}

See Appendix Tables A1-A4

Table A1

Significant correlations between dI/GDP and selected macroeconomic indicators (Traditional market economies, 1970-2011).

\begin{tabular}{|c|c|c|c|c|c|c|c|c|c|}
\hline & PC & GC & GFCF & OPEN & CAPITA & GROW & TTR & MFG & TRADE \\
\hline Australia & -0.358 & -0.423 & & & & 0.598 & & & \\
\hline Belgium & & -0.513 & 0.57 & -0.33 & -0.423 & 0.566 & -0.619 & 0.556 & \\
\hline Canada & & -0.449 & & & & 0.702 & & 0.392 & 0.398 \\
\hline Denmark & & -0.428 & 0.411 & & & 0.537 & & & \\
\hline Finland & & -0.554 & 0.334 & & & 0.457 & -0.491 & 0.469 & \\
\hline France & -0.561 & -0.716 & 0.65 & -0.31 & -0.371 & 0.817 & -0.568 & 0.472 & \\
\hline Germany & & -0.322 & 0.628 & -0.454 & -0.586 & 0.591 & -0.546 & 0.665 & 0.486 \\
\hline Iceland & & & 0.331 & & & & & & \\
\hline Israel & -0.382 & & & & -0.56 & & 0.807 & & \\
\hline Italy & & & & & & 0.523 & & & \\
\hline Japan & -0.84 & -0.722 & 0.748 & & -0.666 & 0.502 & -0.581 & 0.725 & \\
\hline Netherlands & & & & & & 0.545 & & & \\
\hline New Zealand & & & & & & 0.527 & & & \\
\hline Norway & & -0.307 & & & & & & & \\
\hline Spain & 0.4 & -0.635 & & -0.515 & -0.464 & & -0.625 & & \\
\hline Sweden & & -0.627 & 0.379 & -0.315 & -0.394 & 0.374 & -0.575 & 0.65 & \\
\hline UK & & -0.446 & & & & 0.664 & & & \\
\hline USA & -0.408 & & 0.348 & & -0.332 & 0.788 & & 0.373 & 0.519 \\
\hline
\end{tabular}

Bold values indicate significant linear correlations at a $p=0.01$ level, while the remaining values show linear correlations at a $p=0.05$ level. 
Table A2

Significant correlations between dI/GDP and the selected macroeconomic indicators (Traditional market economies, 1970-1993).

\begin{tabular}{|c|c|c|c|c|c|c|c|c|c|}
\hline & PC & GC & GFCF & OPEN & CAPITA & GROW & TTR & MFG & TRADE \\
\hline Australia & -0.612 & -0.451 & & & & 0.616 & & & \\
\hline Belgium & $-\mathbf{0 . 6 1 1}$ & -0.53 & 0.596 & -0.482 & -0.638 & 0.514 & -0.706 & 0.701 & \\
\hline Canada & & -0.68 & 0.407 & & -0.438 & 0.777 & -0.449 & 0.56 & 0.53 \\
\hline Denmark & 0.443 & -0.456 & 0.489 & & -0.457 & 0.574 & & 0.531 & 0.516 \\
\hline Finland & & -0.628 & 0.448 & & -0.437 & 0.469 & -0.65 & 0.598 & \\
\hline France & -0.639 & -0.787 & 0.718 & -0.516 & -0.612 & 0.883 & -0.665 & 0.666 & \\
\hline $\begin{array}{l}\text { Germany } \\
\text { Iceland }\end{array}$ & & -0.55 & 0.61 & -0.655 & -0.691 & 0.564 & $\begin{array}{r}-\mathbf{0 . 5 8 8} \\
0.525\end{array}$ & 0.784 & 0.677 \\
\hline \multicolumn{10}{|l|}{ Israel } \\
\hline Italy & & & & & & 0.662 & & & \\
\hline Japan & -0.851 & -0.833 & 0.764 & & -0.538 & & -0.567 & 0.776 & \\
\hline Netherlands & & & & & & 0.549 & & & \\
\hline New Zealand & & & & & & 0.533 & & & \\
\hline Norway & 0.522 & -0.493 & & & & & -0.456 & -0.466 & 0.6 \\
\hline Spain & & -0.625 & 0.762 & -0.605 & -0.485 & & -0.545 & & \\
\hline Sweden & & -0.674 & 0.496 & & -0.583 & & -0.623 & 0.754 & \\
\hline UK & & -0.467 & & & & 0.667 & & & \\
\hline USA & -0.405 & & & & & 0.697 & & & \\
\hline
\end{tabular}

Bold values indicate significant linear correlations at a $p=0.01$ level, while the remaining values show linear correlations at a $p=0.05$ level

Table A3

Significant correlations between dI/GDP and the selected macroeconomic indicators (Traditional market economies, 1994-2011).

\begin{tabular}{|c|c|c|c|c|c|c|c|c|c|}
\hline & PC & GC & GFCF & OPEN & CAPITA & GROW & TTR & MFG & TRADE \\
\hline Australia & & & & -0.624 & & 0.675 & & & \\
\hline Belgium & & & & & & 0.652 & & & \\
\hline Canada & & & & & & 0.539 & & & \\
\hline Denmark & & -0.704 & 0.629 & & & 0.534 & & & \\
\hline Finland & & & & & & 0.571 & & & \\
\hline France & -0.604 & -0.684 & & 0.666 & & 0.597 & 0.495 & & \\
\hline Germany & -0.486 & -0.626 & & & & 0.579 & & & \\
\hline \multicolumn{10}{|l|}{ Iceland } \\
\hline Israel & -0.587 & 0.479 & & & -0.56 & & 0.807 & & \\
\hline Italy & & & & & & 0.619 & & & \\
\hline Japan & -0.61 & & & & & 0.513 & & & \\
\hline Netherlands & & & & & & 0.714 & & & \\
\hline New Zealand & & -0.658 & & & -0.54 & 0.683 & & 0.641 & \\
\hline Norway & -0.582 & & & & 0.667 & & & 0.577 & \\
\hline \multicolumn{10}{|l|}{ Spain } \\
\hline Sweden & & & & & & 0.711 & & 0.859 & -0.61 \\
\hline UK & & -0.629 & & & & 0.817 & & & \\
\hline USA & -0.613 & -0.566 & & & -0.487 & 0.946 & 0.529 & 0.746 & 0.762 \\
\hline
\end{tabular}

Bold values indicate significant linear correlations at a $p=0.01$ level, while the remaining values show linear correlations at a $p=0.05$ level

Table A4

Significant correlations between dI/GDP and the selected macroeconomic indicators (Post-socialist economies, 1994-2011).

\begin{tabular}{|c|c|c|c|c|c|c|c|c|c|}
\hline & PC & GC & GFCF & OPEN & CAPITA & GROW & TTR & MFG & TRADE \\
\hline Czech Republic & -0.584 & & & & & 0.668 & & & \\
\hline Estonia & & & & 0.605 & & 0.909 & & & \\
\hline Hungary & & & & & & 0.796 & & 0.642 & \\
\hline Poland & & & & & & 0.639 & & & -0.523 \\
\hline Slovakia & & & & 0.587 & & & & & \\
\hline Slovenia & -0.545 & -0.489 & & 0.545 & & 0.61 & & & \\
\hline
\end{tabular}

Bold values indicate significant linear correlations at a $\mathrm{p}=0.01$ level, while the remaining values show linear correlations at a $p=0.05$ level.

\section{References}

Bergson, A., 1989. Planning and Performance of Socialist Economies: USSR and Eastern Europe. Unwin Hyman, London.

Bils, M., Kahn, J.A., 2000. What inventory behaviour tells us about business cycles. Am. Econ. Rev. 90 (3), 458-481.

Blinder, A.S., 1980. Inventories and the structure of macro models. NBER Working
Paper Series, July (525).

Blinder, A.S., Maccini, L.J., 1991. Taking stock: a critical assessment of recent research on inventories. J. Econ. Perspect. 5 (1), 73-96. http://dx.doi.org/10.1257/ jep.5.1.73.

Bouthevillain, C., Eyssartier, D., 1997. Le rôle des variations de stocks dans les cycles d'activité desprincipaux pays industrialisés. Rev. De. l'OFCE 62 (1), 151-202.

Chikán, A., 1981. Market disequilibrium and the volume of stocks. In: Chikán, A

(Ed.), The Economics and Management of Inventories. Elsevier, Amsterdam, 
pp. $73-85$.

Chikán, A., 1990. Inventory Structure in the Manufacturing Industry. A CrossCountry Comparison. Budapest University of Economics, Budapest.

Chikán, A., 1994. Joint micro and macro effects of inventories in the transition economies. Int. J. Prod. Econ. 1-3, 11-14.

Chikán, A., 1996. Some micro explanations of global inventory trends. In: Chikán, A. Milne, A., Sprague, L.G. (Eds.), Reflections on Firm and National Inventories. ISIR, Budapest, pp. 1-7.

Chikán, A., 2007. The new role of inventories in business: real world changes and research consequences. Int. J. Prod. Econ. 108, 54-62.

Chikán, A., Kovács, E., 2009. Inventory investment and GDP characteristics in OECD countries. Int. J. Prod. Econ. 118 (1), 2-9.

Chikán, A., Kovács, E., Matyusz, Z., 2011. Inventory investment and sectoral characteristics in some OECD countries. Int. J. Prod. Econ. 133 (1), 2-11.

Clausen, J.R., Hoffmaister, A.W., 2010. Cyclical behavior of inventories and growth projections: recent evidence from Europe and the United States. IMF Working Paper, September (WP/10/212)

Fiorito, R., 2003. Inventory changes and the closing of macroeconometric models. Int. J. Prod. Econ. 81-82, 75-84.

Forrester, J.W., 1976. Business structure, economic cycles, and national policy. Futures 8 (3), 195-214.

Ghebrihiwet, N., 2011. Inventories and the business cycle. Analysing Dutch inventories. Discussion Paper (201116). The Hague/Heerlen: Statistics Netherlands, Available 〈http://www.cbs.nl/NR/rdonlyres/83E9153d-01A9-4DA3-AC16F659F08679C2/0/2011x1016.pdf).

Guasch, J.L., Kogan, J., 2001. Inventories in developing countries: levels and determinants-a red flag on competitiveness and growth. World Bank Policy Research Working Paper, (WPS 2552).

Hall, R.W., 1983. Zero Inventories. Dow Jones-Irwin, Homewood.

Hay, D., Louri, H., 1996. Demands for short-term assets and liabilities by UK quoted companies. Appl. Financ. Econ. 6 (5), 413-420.

Hofer, C., Eroglu, C., Hofer, A.R., 2012. The effect of lean production on financia performance: the mediating role of inventories. Int. J. Prod. Econ. 38 (2), $242-253$.

Kahn, J.A., 1992. Why is production more volatile than sales? Theory and evidence on the stockout-avoidance motive for inventory-holding. Q. J. Econ. 107 (2),
$481-510$.

Kaneko, Y., 2005. Deflation and inventory investment. JCER Researcher Report, June (61).

Khan, A., Thomas, J.K., 2004, Modeling inventories over the business cycle. NBER Working Paper Series, July (10652).

Kornai, J., 1971. Anti-Equilibrium: on Economic Systems Theory and the Tasks of Research. North-Holland Publishing, Amsterdam.

Kornai, J., 1980. Economics of Shortage. North Holland, Amsterdam.

Lee, H.L., Billington, C., 1992. Supply chain management: pitfalls and opportunities. Sloan Manag. Rev. 33 (3), 65-73.

Lovell, M.C., 1994. Researching inventories: why haven't we learned more? Int. J. Prod. Econ. 35 (1-3), 33-41.

Lovell, M.C., 1996. Macroeconomic implications of S, s versus accelerator finished goods inventory strategies. Int. J. Prod. Econ. 45 (1-3), 55-64.

Maccini, L.J., Pagan, A., 2013. Inventories, fluctuations, and goods sector cycles. Macroecon. Dyn. 17 (1), 89-122.

Maddala, G.S., 2001. Introduction to Econometrics, third ed. John Wiley \& Sons, New York.

Markowitz, H.M., 1959. Portfolio selection: efficient diversification of investments. John Wiley \& Sons, New York.

McCarthy, J., Zakrajsek, E., 1999. Microeconomic inventory adjustment and aggregate dynamics. BIS Working Papers, March (63).

Ministry of Petroleum and Energy, 2013. Norway's Oil History in 5 min. Available: 〈http://www.regjeringen.no/en/dep/oed/Subject/oil-and-gas/norways-oil-his tory-in-5-minutes.html?id=440538 $\rangle$. Accessed: 24/09/2014.

Organisation for Economic Co-operation and Development (OECD), 2013. OECD statistics. Available: 〈http://stats.oecd.org $\rangle$. Accessed: 27/09/2013.

Prahalad, C.K., Hamel, G., 1990. The core competence of the corporation. Harv. Bus. Rev. 68 (3), 79-91.

Ramey, V.A., West, K.D., 1997. Inventories. NBER Working Papers, December (6315).

Siems, T.F., 2005. Who supplied my cheese? Supply chain management in the global economy. Bus. Econ., 6-21.

Wen Y., 2007. Granger causality and equilibrium business cycle theory. Federal Reserve Bank of St. Louis Review. 893 pp. 195-205.

Wooldridge, J.M., 2002. Econometric Analysis of Cross Section and Panel Data. MIT Press, Cambridge, MA. 